\title{
SOBRE A CONCORDÂNCIA MODAL EM PORTUGUÊS
}

\author{
(On modal concord in Portuguese)
}

\author{
Marcus Vinicius Lunguinho ${ }^{1}$ \\ (Universidade de São Paulo - USP)
}

\begin{abstract}
In this paper I discuss modal concord in Portuguese. This phenomenon, initially described by Halliday (1970), is characterized by the syntactic presence of two modal elements which are interpreted as if there was just one of them. Based on Kratzer's $(1981,1991)$ theory of Modality, I analyze Portuguese data and point out, in accordance with the literature (Geurts \& Huitink 2006, Zeijlstra 2007 e Huitink 2009), that modal concord obeys two constraints: a) one of the modal elements must be a modal auxiliary verb, and b) the modal elements must share the same modal force and type of modality.
\end{abstract}

Keywords: modal auxiliaries, modal concord, modality, quantification.

\section{RESUMO}

Nesse artigo, discuto a concordância modal em Português. Esse fenômeno, inicialmente descrito por Halliday (1970), se caracteriza pela presença sintática de dois itens modais que são interpretados como se houvesse apenas um. Com base na teoria da Modalidade de Kratzer (1981, 1991), analiso os dados do Português e destaco, em consonância com a literatura (Geurts \& Huitink 2006, Zeijlstra 2007 e Huitink 2009), que a concordância modal obedece a duas restrições: a) um dos elementos modais deve ser

1. Este trabalho, que constitui um recorte de minha pesquisa de Doutorado em andamento, contou com o apoio financeiro da CAPES (Bolsa de Doutorado Sanduíche: PDEE 2369/09-5) e da FAPESP (Bolsa de Doutorado no País: BP.DR2 2007-58451-7). Agradeço imensamente à professora Denize Elena Garcia da Silva, pelo incentivo que me deu para escrever sobre o tema da modalidade. Todos os problemas, erros e inadequações são de minha inteira responsabilidade. 
um verbo auxiliar modal e b) os elementos modais devem compartilham a mesma força modal e o mesmo do tipo de modalidade.

Palavras-chave: concordância modal, modalidade, quantificação, verbos auxiliares modais.

\section{Introdução}

Nesse artigo, trato de um fenômeno gramatical denominado concordância modal, fenômeno esse que, de acordo com a literatura (Halliday 1970, Lyons 1977, Geurts \& Huitink 2006, Zeijlstra 2007, Huitink 2009), existe tanto em Inglês quanto em Holandês. Tendo em vista que existe concordância modal nessas duas línguas, uma pergunta se coloca: existe concordância modal em Português? O propósito do presente estudo é, pois, aproximar respostas à referida questão que, pela primeira vez, parece ser tratada no âmbito da língua portuguesa.

$\mathrm{O}$ artigo se estrutura como a seguir. Na Seção 2 trato do fenômeno de concordância modal tal qual descrito por Halliday (1970) para o Inglês. Na Seção 3 apresento a noção de modalidade que usarei para entender o fenômeno de concordância modal. Na Seção 4 descrevo os aspectos estruturais da concordância modal. Na Seção 5 analiso que traços semânticos estão envolvidos nessas construções. $\mathrm{Na}$ Seção 6 apresento brevemente o efeito discursivo associado às sentenças com concordância modal. Por fim, na Seção 7, resumo as ideias gerais do presente estudo.

\section{A concordância modal e seu estudo}

O fenômeno que aqui será analisado foi observado pela primeira vez por Halliday (1970) e depois por Lyons (1977), para o Inglês. Recentemente foi retomado e recebeu análises tanto da parte de Geurts \& Huitink (2006), que também propuseram dar-lhe o nome de concordância modal (do inglês, modal concord), quanto da parte de Zeijlstra (2007). O exemplo que Halliday (1970: 328) usa para ilustrar o fenômeno por ele descoberto é o seguinte: 
1. Possibly this gazebo may have been built by Sir Christopher Wren.

Segundo Halliday, a sentença em (1) tem as sentenças em (2) como possíveis contrapartes:

2. a. Possibly this gazebo was built by Sir Christopher Wren. b. This gazebo may have been built by Sir Christopher Wren.

O que chama atenção no dado em (1) é que, apesar da presença de dois itens modais (o advérbio e o verbo modal), isso não implica que esse exemplo seja duplamente modal; pelo contrário, a sentença é interpretada como se houvesse apenas um deles, conforme vemos nas contrapartes apresentadas em (2). Tal se dá porque em (1) operou a concordância modal que faz com que dois itens modais que estão realizados na sintaxe sejam interpretados como se fossem apenas um.

A concordância modal não é um processo obrigatório. Como o próprio Halliday (1970: 331) mostra, quando da presença de um verbo auxiliar modal e de um advérbio, é possível que o resultado seja uma interpretação composicional (também chamada cumulativa) ${ }^{2}$ :

(1) Certainly he might have built this gazebo.

a. I insist that it is possible that he have built this gazebo.

b. I grant that it is possible that he have built this gazebo.

A contribuição de cada palavra modal fica explícita nas paráfrases (a) e (b) acima: certainly traz a ideia de certeza (I insist /grant that...), e o auxiliar might se associa à ideia de possibilidade (...it is possible that...). Dizemos que a interpretação nesse caso é composicional, cumulativa, uma vez que cada uma das palavras modais contribui para a interpretação da sentença como um todo.

2. Conforme aponta Zeijlstra (2007), quando combinamos um verbo auxiliar modal e um advérbio modal, o resultado mais comum é a interpretação composicional e não a concordância modal. 
Com esses exemplos, Halliday (1970: 331) define dois efeitos interpretativos que podem surgir quando da combinação de elementos modais, quais sejam, a interpretação composicional e a interpretação resultante de concordância modal:

“(...) a clear distinction can be drawn between pairs which are felt to be equivalent, and thus reinforce each other (as 'concord') when both are present, as in perhaps he might have built it, and those which are nor equivalent and are thus cumulative in meaning, as in certainly he might have built it (...)"

Uma vez apresentado o fenômeno de concordância modal tal qual foi proposto para o Inglês, cabe indagarmos se esse fenômeno também existe em Português. Como vimos na Introdução, esse artigo é uma tentativa de responder a essa questão. Antes, porém, de respondêla, apresento brevemente, na seção seguinte, as bases da teoria sobre modalidade que usarei no decorrer do artigo.

\section{Da Modalidade}

O estudo da categoria modalidade remonta, no Ocidente, à tradição lógico-filosófica da Grécia Antiga. Desde então, tem se tornado um tópico de intensos debates tanto no campo da Lógica Formal quanto no da Lingüística. No que tange à expressão da modalidade nas línguas naturais, muitos são os enfoques: tipológicodescritivos, diacrônicos, funcionalistas, formalistas, cognitivistas. Não é possível resenhar aqui todos esses olhares sobre a modalidade e, devido a isso, limito-me a apresentar a noção de modalidade com a qual estarei lidando no decorrer do artigo.

\subsection{A noção de modalidade: meios de expressão e tipos de modalidade}

Segundo von Fintel (2006), a modalidade é uma categoria lingüística cujo significado tem a ver com a expressão de possibilidades e necessidades. Essa categoria tem como contraparte a categoria 
da temporalidade (tempo e aspecto) e, juntas, elas constituem parte essencial daquilo que Charles Hockett (1960) denominou propriedade do deslocamento, característica das línguas humanas por meio da qual superamos as fronteiras do aqui e agora em que estamos inseridos e somos capazes falar de coisas que estão muito além de nossa realidade presente e factual.

As línguas humanas usam vários meios para expressar a modalidade: Em Português, usamos os seguintes (os exemplos são baseados em Kratzer 1991, von Fintel 2006 e Hacquard no prelo, e não pretendem ser exaustivos):

(4) Meios de expressão da modalidade em Português

a. Afixo - vel $^{3}$ : Esse tecido é lavável $=$ Esse tecido pode ser lavado.

Sua atitude foi lamentável $=$ Sua atitude deve ser lamentada.

b. Substantivos: necessidade, possibilidade, obrigação, probabilidade...

c. Verbos auxiliares modais: poder, dever, ter que/ter de

d. Adjetivos: (im)possivel, necessário, provável, capaz, obrigado...

e. Advérbios: obrigatoriamente, possivelmente, provavelmente, necessariamente, talvez...

f. Construções impessoais: ser possível que, ser provável que, ser certo que, ser necessário que, ser obrigatório que, pode ser que, dar para,...

g. Orações condicionais: Se a porta está aberta, (então) alguém está aqui.

A modalidade não é uma categoria única. Existem vários tipos de modalidade, mas, em geral, dois são mais proeminentes: a modalidade

3. A respeito da semântica associada ao sufixo -vel em Português, ver Oliveira \& Ngoy (2007). 
epistêmica e a modalidade deôntica. A modalidade epistêmica é o domínio das possibilidades e necessidades em vista do conhecimento do falante ou das evidências disponíveis no mundo. A modalidade deôntica se relaciona com o possível, o necessário e o permitido dado um certo conjunto de leis, princípios morais ou regras. Além desses dois tipos, existem pelo menos mais três: a modalidade habilitativa, a modalidade boulética e a modalidade teleológica.

A modalidade habilitativa, circunstancial ou dinâmica (Palmer 1986) tem a ver com o que é possível dadas certas circunstâncias físicas ou habilidades do sujeito. A modalidade boulética ou boulemaica trata do que é necessário ou possível em relação aos desejos de alguém. Por fim, a modalidade teleológica ou orientada para um alvo (von Fintel \& Iatridou 2005, Hacquard 2006) é o domínio do necessário e do possível com vistas ao alcance de um dado objetivo. Cada uma das modalidades é apresentada nos exemplos a seguir (forneço entre parênteses informação necessária para a fácil apreensão do tipo de modalidade exemplificado):

5. Modalidade Epistêmica

(Em vista das evidências disponíveis) Pode / deve / tem que haver alguém em casa.

6. Modalidade Deôntica

(Dadas as regras do jogo) Você pode / deve / tem que indicar alguém para ficar sem jogar essa partida.

7. Modalidade Habilitativa, Circunstancial ou Dinâmica (Em virtude de seu treinamento) $\mathrm{O}$ mergulhador pode ficar até 5 minutos embaixo da água.

8. Modalidade Boulética ou Boulemaica

(Tendo em vista o meu desejo de chegar no horário à reunião) Eu devo / tenho que sair de casa agora.

9. Modalidade Teleológica ou Orientada para um Alvo (Tendo em vista o meu objetivo de passar em um bom concurso) Eu devo / tenho que estudar firme. 


\subsection{A expressão da modalidade pelos verbos auxiliares modais}

Como veremos mais adiante, os verbos auxiliares modais são peça importante para o fenômeno da concordância modal. Sendo assim, apresento nessa seção como eles são tratados na literatura, pois isso vai nos ajudar na compreensão do fenômeno em estudo.

Comecemos com os exemplos (5) a (9) acima. Neles vemos que os verbos modais poder, dever e ter que podem expressar variados tipos de modalidade: poder expressa a modalidade epistêmica, a deôntica e a circunstancial; dever e ter que expressam a modalidade epistêmica, a deôntica, a teleológica e a boulética. A pergunta que nos fazemos nesse momento é: de onde vem toda essa riqueza interpretativa dos modais?

Existem pelo menos duas maneiras de respondermos a essa pergunta. A primeira possibilidade é localizarmos no Léxico todas essas interpretações por meio da postulação de homonímia, polissemia ou ambigüidade no domínio dos verbos modais. Uma segunda possibilidade (e que será adotada aqui) foi proposta por Kratzer (1977, 1981, 1991) no contexto de sua teoria geral da modalidade. Para essa autora, os verbos modais não são nem homônimos, nem ambíguos e nem polissêmicos; eles são quantificadores ${ }^{4}$ que quantificam sobre mundos possíveis 5 . Como quantificadores, eles podem ser de dois tipos: quantificadores existenciais e quantificadores universais. Ilustremos isso com os dados a seguir:

(10) a. O João deve / tem que comer frutas.

b. O João pode comer frutas.

Em (10a) dizemos que a proposição "o João comer frutas" é verdadeira em todos os mundos possíveis e, em (10b), afirmamos que a mesma proposição é verdadeira em pelo menos um mundo possível.

4. Kratzer resgata esse tratamento quantificacional dos modais dos trabalhos em Lógica Modal.

5. O termo mundos possíveis é de Lewis (1973) e tem a ver com as mais variadas maneiras como o mundo poderia ser organizado. 
Disso podemos concluir que a contribuição dos modais é apenas a quantificação que eles introduzem: dever e ter que são quantificadores universais e poder é um quantificador existencial. Kratzer aposta na ideia de que esse é o único traço que os modais trazem do Léxico e denomina essa informação de força quantificacional do modal e é o primeiro ingrediente que precisamos conhecer para entendermos uma sentença com um verbo modal.

Com essa explicação, ainda não temos uma resposta para a questão das origens das variadas interpretações que atribuímos a um verbo modal.

Nesse ponto, entra o segundo ingrediente da proposta de Kratzer: o contexto. ${ }^{6}$ Para ela, os modais são verbos altamente dependentes do contexto, uma vez que é o contexto que fornece a informação necessária para completar a interpretação de uma sentença modalizada. Um argumento em favor dessa proposta vem do fato de uma sentença com um verbo modal como (11) poder se associar a várias situações diferentes:

(11) O nosso sócio pode revelar nossos planos.

Situação 1: Sabemos que o nosso sócio não consegue guardar segredo porque já tivemos incidentes anteriores em que ele revelou nossos planos aos nossos concorrentes. Logo, em vista das evidências disponíveis sobre o comportamento do nosso sócio, é possível que ele revele os nossos planos.

Poder veicula a modalidade epistêmica.

Situação 2: Temos um contrato e, segundo uma de suas cláusulas, o nosso sócio é livre para revelar os nossos

6. Para ser mais preciso, o papel do contexto é restringir os tipos de mundos sobre os quais o modal vai quantificar (por meio da relação de acessibilidade) e, depois de escolhidos esses mundos, eles serão ordenados (pela fonte de ordenação) de acordo com a proximidade a um mundo ideal. Para mais detalhes, consultar Kratzer (1991). 
planos a quem ele quiser. Logo, em vista das leis que regem o nosso contrato, é permitido que o nosso sócio revele os nossos planos.

Poder veicula a modalidade deôntica.

Situação 3: Nosso sócio conhece, e muito bem, os nossos planos. Ele, inclusive, contribuiu com a maior parte das ideias que fazem parte desse plano. Logo, em vista das circunstâncias, o nosso sócio é capaz de revelar os nossos planos.

Poder veicula modalidade circunstancial (capacidade).

Como podemos observar, uma mesma frase contendo um verbo modal é perfeitamente aceitável em diferentes cenários. Isso dá maior credibilidade à proposta de Kratzer de que o contexto contribui com informações que vão resultar no tipo de interpretação que o modal vai ter. Dessa forma, a interpretação final das sentenças com verbos modais é resultado da articulação de dois componentes: a força quantificacional do modal (que é dada lexicalmente e que é constante) e o contexto discursivo (que vai contribuir com a informação lingüisticamente presente ou apenas partilhada pelos interlocutores).

Apresentada a noção básica de modalidade com a qual lido nesse artigo bem como as características básicas dos modais na proposta de Kratzer, podemos passar aos dados sobre concordância modal em Português.

\section{A concordância modal em português: dados e descrição estrutural}

Nessa seção respondo à pergunta que motiva o presente estudo, qual seja, existe concordância modal em Português? Como veremos, da mesma forma que em Inglês e em Holandês, em Português também há concordância modal. Antes de apresentar os exemplos, 
teço comentários metodológicos sobre a fonte da qual eles foram extraídos.

Todos os exemplos do Português que serão apresentados nesse trabalho foram colhidos da internet, do site do Yahoo!, especificamente do Yahoo! Respostas, uma comunidade na qual os internautas fazem perguntas visando receber respostas da parte de outros internautas. Os dados selecionados para a análise têm duas características: a) são dados reais, produzidos por falantes da língua portuguesa e b) predomina neles um tipo de linguagem próximo do coloquial. Em relação à apresentação dos dados, um comentário se faz pertinente. Como vimos na seção anterior, o contexto é um ingrediente fundamental para a delimitação da interpretação de um verbo modal, assim, para facilitar a apreensão do tipo de modalidade envolvida, os dados trazem o contexto da pergunta e da resposta, identificados pelas letras $P$ e $R$, respectivamente. Para esse trabalho, baseio-me unicamente nas respostas dos internautas, razão pela qual todas as afirmações que eu fizer nesse artigo serão feitas com base no material colhido nas respostas. Os exemplos sofreram mínimas adaptações de forma, tais como correções ortográficas, substituição de abreviaturas comuns, inclusão de acentos, flexões e sinais de pontuação. Trechos irrelevantes foram omitidos e essa omissão é sinalizada pelas reticências dentro de parênteses. Dito isso, passemos à apresentação dos exemplos de concordância modal em Português:

(12) $\boldsymbol{P}$ : Hoje fui fazer uma caminhada com meu pai (...) $2 \mathrm{~km}$ mais ou menos à beira do rio daqui da cidade. Quando a gente estava chegando em casa, minha vista começou a escurecer e comecei a me tremer...Quase caí no chão. O que será que pode ser?

$\boldsymbol{R}$ : Olá, tudo bem? Então, possivelmente pode ter sido uma queda de pressão ou hipoglicemia, ou seja, você provavelmente não se alimentou direito ou até mesmo não comeu nada (...)

a. ...possivelmente foi uma queda de pressão...

b. ...pode ter sido uma queda de pressão... 
c. \# ...é possível que seja possível que tenha sido uma queda de pressão ${ }^{7}$...

(13) P: Quais são os procedimentos que um Assistente Social deve tomar no caso de falecimento do pai de um empregado? Sou estagiária de Serviço Social em uma empresa e faleceu o pai de um empregado, e gostaria de saber como tratar a situação. Por onde começar?

$\boldsymbol{R}$ : Se você é estagiária, obrigatoriamente deve ter uma supervisora, seja em seu trabalho, seja na faculdade em que estuda. Essa orientadora, que deve ser uma Assistente Social formada, é quem a irá orientar conforme as determinações legais do MEC.

a. Se você é estagiária, obrigatoriamente tem uma supervisora...

b. Se você é uma estagiária, deve ter uma supervisora...

c. \#Se você é estagiária, é necessário que seja obrigatório que você tenha uma supervisora...

Como vemos, os dois itens modais (o auxiliar modal e o advérbio) podem ser substituídos por paráfrases nas quais há apenas um elemento modal. A leitura cumulativa presente nas paráfrases em (c) não é possível. Esse fato nos leva a concluir que há seqüências de itens modais em Português que podem receber uma interpretação resultante de concordância modal. Uma vez que sabemos que existe concordância modal em Português, nas seções seguintes descrevo três aspectos estruturais do fenômeno em estudo.

\subsection{A presença do auxiliar modal}

Vimos na Seção 1, que em todos os exemplos de concordância modal apresentados por Halliday (1970) existem verbos auxiliares modais. Isso não é por acaso, a literatura subseqüente (Geurts \&

7. Usarei o símbolo "\#” para mostrar que no contexto considerado a paráfrase não é aceitável. 
Huitink 2006, Zeijlstra 2007 e Huitink 2009) sustenta que tais verbos constituem peça fundamental para o estabelecimento da concordância modal. Essa situação também acontece em Português dado que nos exemplos (12) e (13) também aparecem auxiliares modais. Vou assumir que em Português também seja assim. Com isso, começamos a desvendar a estrutura das construções em que se verifica concordância modal: nesses dados é necessária a articulação de dois elementos modais, um dos quais deve ser um verbo auxiliar modal.

\subsection{A natureza do segundo elemento modal}

Uma vez que sabemos que precisamos de dois elementos modais e que um deles deve ser um auxiliar, cabe agora sabermos qual a natureza do outro elemento que acompanha o auxiliar modal e gera os efeitos de concordância modal. Pelos próprios exemplos apresentados em (12) e (13), o outro elemento que acompanha o auxiliar modal pode ser um advérbio, mas também existe a possibilidade de esse segundo elemento ser um outro verbo modal, como o dado do Holandês ilustra ${ }^{8}$ :

(14) Dat zou kunnen gebeuren. (Zeijlstra 2007: 325) Aquilo ia poder acontecer 'Aquilo (realmente) podia acontecer'

Haveria em Português essa segunda possibilidade? Seqüências de modais existem em Português, como pode ser visto nos exemplos abaixo":

8. Em Inglês não existe essa possibilidade devido a propriedades particularidades da sintaxe dos modais ingleses especificamente o fato de eles serem verbos com um paradigma morfológico defectivo que não apresenta as formas não-finitas (infinitivo, gerúndio e particípio). Como depois de um modal, sempre vem uma forma não-finita, os modais ingleses automaticamente estão excluídos de aparecer nessa posição, pois o contexto exigiria essa forma que não existe em seu paradigma morfológico (sobre a defectividade dos modais ingleses, ver McCawley 1971, Pullum \& Wilson 1977, Lightfoot 1979, 1991, Baker 1981, Schachter 1983, Roberts 1985, Roberts \& Roussou 2003, Stowell 2004).

9. Conforme já apontaram Tavares de Macedo (1972), Pontes (1973), Lobato (1975), Miranda (1975) e Lunguinho (2005). 
(15) P: O que é cartão de débito? Como funciona o cartão de débito? É mais seguro do que o cartão de crédito?

$\boldsymbol{R}$ : Sim. Cada vez que você compra alguma coisa, desconta o valor direto na sua conta no banco. Eu diria que é mais seguro que o cartão de crédito porque você não vai gastar o que não tem. No cartão de crédito, você faz uma compra a longo prazo e pode não poder pagar.

(16) P: O que é SCIH e seu funcionamento?

$\boldsymbol{R}$ : Deve ser alguma coisa do governo, tipo um imposto. Porque o governo adora siglas, e você deve ter que ir pagar na prefeitura.

(17) P: O que você procura ou quer comprar na internet e não encontra? Atualmente as lojas online são a tendência para as pessoas comprarem de tudo sem sair de casa, trabalho ou seja lá onde for. Em cima disso, estou fazendo um estudo para saber com que freqüência você compra coisas pela internet, que tipo de pagamento costuma usar, o que costuma comprar e principalmente: o que é complicadíssimo de se encontrar na internet? Obrigado.

$\boldsymbol{R}:$ (...) Acho, porém, que um dos pontos mais graves e sensíveis para o cliente que os empresários do e-shopping têm que melhorar, e muito, é o processo de entrega: em primeiro lugar, o cliente tem que poder rastrear a entrega com mais detalhes e, em segundo, a data e, pelo menos, a parte do dia (manhã, tarde) deve poder ser acertada.

Os exemplos acima mostram que a presença de dois verbos modais não necessariamente implica concordância modal. Nesses exemplos, a leitura mais saliente é a de cumulatividade, em que cada modal apresenta sua contribuição à interpretação do todo. Em (15), os dois modais poder apresentam diferentes leituras; o primeiro tem uma leitura epistêmica e o segundo tem uma leitura circunstancial: "usando o cartão de crédito, você faz uma compra a longo prazo e é possivel que 
você não seja capaz de pagá-la”. No exemplo (16), dever é interpretado como epistêmico e ter que como deôntico: "provavelmente é necessário ir pagar na prefeitura”. O exemplo (17) traz as combinações restantes, ter que e poder de um lado e dever e poder de outro. Na primeira seqüência de modais, ter que é interpretado como modal deôntico e poder é interpretado ou como circunstancial ou deôntico: "é necessário que o cliente seja capaz de rastrear a entrega" ou "é necessário que seja permitido ao cliente rastrear a entrega". No caso da combinação de dever e poder, ambos têm interpretação deôntica: "é necessário que seja permitido que a data e, pelo menos, a parte do dia (manhã, tarde) seja acertada”.

Ao lado de dados como os acima, foram encontradas seqüências nas quais dever e ter que co-ocorrem e cuja interpretação parece ser resultado de concordância modal:

(18) P: Professores da rede pública ganham benefícios como vale alimentação etc?

$\boldsymbol{R}$ : Bom dia!!!! (...) professores que trabalham na rede estadual não têm o direito de vale alimentação (...) Não temos direito a vale transporte (...) Um dos benefícios que nós temos é plano de saúde médica onde todos os meses eles descontam 5\% do nosso salário bruto. Ou seja, se quiser ser professor de algo você deve ter que adorar o seu conteúdo e ter muita, mas muita vontade de dar aulas, porque, se depender do estado, as escolas irão acabar.

a. (...) se quiser ser professor de algo você deve adorar o seu conteúdo (...)

b. (...) se quiser ser professor de algo você tem que adorar o seu contéudo (...)

(19) P: Queria ser piloto de helicóptero, que devo fazer? Gostaria de saber que grau de escolaridade precisa pra fazer um curso de piloto, preço do curso, carga horária e se é fácil conseguir um serviço de piloto, uma vez que tenha terminado o curso. Muito obrigado. 
$\boldsymbol{R}:$ Deve ter que ter um grau de escolaridade avançado. No Campo de Marte na cidade de São Paulo, eles dão esse curso. Você pode se informar lá, se morar em SP.

a. Deve ter um grau de escolaridade avançado.

b. Tem que ter um grau de escolaridade avançado.

Com base nesses dados, pode-se afirmar que o segundo elemento que aparece ao lado de verbos modais, quando há concordância modal, pode ser tanto um advérbio quanto um outro verbo auxiliar modal. Além disso, o contraste observado entre os dados (15-17) e (18-19) fornece evidências para um tratamento da concordância modal como um fenômeno não obrigatório.

\subsection{Da posição dos itens modais}

Como foi evidenciado acima, a concordância modal ocorre quando há dois itens modais: um deles necessariamente um verbo auxiliar modal e o outro ou um advérbio ou um outra instância de um auxiliar modal. Se é necessário que haja esses dois itens modais, cabe perguntarmos se basta a presença deles para que haja concordância modal ou eles devem estar presentes em um certo domínio.

Atentando para todos os exemplos apresentados acima, vemos que os itens modais envolvidos encontram-se sempre muito próximos: sempre na mesma oração. Essa restrição já havia sido notada antes na literatura (Zeijlstra 2007, Huitink 2009). Uma questão que se relaciona com essa é saber se, estando os elementos modais envolvidos na mesma oração, existe alguma exigência de adjacência entre eles.

Parece não ser necessária a adjacência entre os itens envolvidos, em vista dos seguintes exemplos em que o modal e o advérbio aparecem separados pelo sujeito:

(20) P: Sou contador, ganho bem, mas estou pensando em largar tudo para virar piloto de avião o que você acha, como? 
$\boldsymbol{R}$ : Faça o curso de aviador (deve ter noturno) estude muito, se esforce e possivelmente você pode virar um bom piloto particular.

(21) P: Qual nível de inglês é necessário para fazer uma faculdade de tradutor e intérprete?

$\boldsymbol{R}$ : Para fazer a faculdade, o nível básico basta. O importante será a especialização ao longo do curso, onde obrigatoriamente você deverá dominar expressões idiomáticas, verbos em todas as formas possíveis, voz passiva, etc. Você precisará ser um "expert” ainda.

Apresentadas as características estruturais dos dados com concordância modal, a próxima seção vai tratar das características semânticas desses dados.

\section{Traços semânticos na concordância modal}

O que entra em jogo nos exemplos em que há concordância modal? Lembrando que em qualquer tipo de concordância, os elementos envolvidos devem partilhar algum traço, uma pergunta surge: o que as palavras modais partilham e que permite a concordância modal?

A resposta vem da própria teoria de Kratzer (apresentada brevemente na Seção 3). Lembremos-nos de que os verbos modais trazem para a sentença apenas sua informação lexical sobre quantificação sobre mundos e que essa quantificação pode ser universal ou existencial: poder é um quantificador existencial e dever e ter que são quantificadores universais. Advérbios também podem se associar à quantificação: obrigatoriamente se associa à quantificação universal e à modalidade deôntica e o advérbio possivelmente é um quantificador existencial e veicula a modalidade epistêmica. A partir dessa informação, podemos entender o que existe nos exemplos com concordância modal vistos acima e repetidos abaixo: 
(22) a. (...) possivelmente pode ter sido uma queda de pressão (...)

b. (...) estude muito, se esforce e possivelmente você pode virar um bom piloto particular.

c. Se você é estagiária, obrigatoriamente deve ter uma supervisora (...)

d. O importante será a especialização ao longo do curso, onde obrigatoriamente você deverá dominar expressões idiomáticas, verbos em todas as formas possíveis, voz passiva, etc.

Como podemos ver, o verbo auxiliar modal e o advérbio em cada exemplo são compatíveis tanto em força quantificacional quanto em relação ao tipo de modalidade expresso: em (22a,b) eles compartilham a mesma força quantificacional existencial e a modalidade epistêmica; já em (22c,d) eles são quantificadores universais com modalidade deôntica. Nesses casos, a concordância modal opera sem nenhum problema.

O mesmo podemos dizer em relação às combinações entre dever e ter que dos exemplos (18) e (19) que geram concordância modal. Nesses casos, os modais concordam tanto em força quantificacional universal quanto em tipo de modalidade expressa, modalidade deôntica. Esses exemplos contrastam com (16) em que também temos modais dever e ter que, mas que não se verificam os efeitos de concordância modal. A existência desse tipo de dado não é problemática dada à própria natureza não obrigatória da concordância modal. Esse mesmo raciocínio pode ser usado para explicar os dados em (15) em que temos duas instâncias do modal poder sem que haja a concordância modal.

Com essa análise, dados como (17) não podem gerar concordância modal, porque, apesar de os modais concordarem em relação ao tipo de modalidade veiculada (a deôntica), eles não compartilham força quantificacional: ter que e dever são quantificadores universais e poder é existencial.

Nesse contexto, exemplos de particular interesse são os seguintes, que envolvem a combinação do advérbio provavelmente com os modais poder e dever com concordância modal entre eles: 
(23)'P: Alguém conhece algum lugar que venda óculos estilo wayfare (não precisa ser Ray Ban) em Petrópolis ou Curitiba? E de preferência barato! Valeu!

$\boldsymbol{R}$ : Oie, Amiga. Olha, eu achei óticas em Curitiba que provavelmente podem ter esse tipo de óculos.

a. Eu achei óticas em Curitiba que provavelmente têm esse tipo de óculos.

b. Eu achei óticas em Curitiba que podem ter esse tipo de óculos.

c. \#Eu achei óticas em Curitiba que é provável que seja possível que tenham esse tipo de óculos.

(24) P: Um homem que te abandona sem maiores motivos; em seguida resolve voltar. Você não quer. (Ele) acaba tendo relacionamento com outras e depois tenta novamente voltar com você. Esse homem te ama ou só quer prender você a ele?

$\boldsymbol{R}$ : Oi. Veja bem, não que eu esteja contra o cara, eu nem conheço como era a relação de vocês, mas, se ele terminou com você sem motivo algum aparentemente, provavelmente ele deve ter conhecido alguma garota e quis se aproximar dela (...)

a. Provavelmente ele conheceu alguma garota e quis se aproximar dela.

b. Ele deve ter conhecido alguma garota e quis se aproximar dela.

c. \#É provável que seja provável que ele tenha conhecido alguma garota e quis se aproximar dela.

O que interessante desses exemplos é que o mesmo advérbio entra em relação de concordância modal com dois verbos modais com diferente força quantificacional. Como explicar isso? Quanto à modalidade expressa nos exemplos, ela é a mesma, a saber, a modalidade epistêmica.

O fato de haver advérbios que se combinam com os dois tipos de modais já havia sido notado na literatura. Huintink (2009) mostra 
que em Inglês, o advérbio probably, pode participar de concordância tanto com um modal universal (must) quanto com um existencial (may):

(25) a. St. Valentine must probably be turning in his grave. 'São Valentim deve estar se revirando em sua cova'

b. If Dillon does as he did the other night, he may probably visit the bar.

'Se Dillon fizer como ele fez na noite passada, ele pode visitar o bar'

(Huitink, 2009: 2010)

A situação do Inglês se assemelha muito à situação do Português em que provavelmente pode-se combinar tanto com poder quanto com dever. Para explicar os fatos do Português, vou assumir com Huitink que "talvez o verbo e o advérbio só tenham que ser "próximos o bastante' em força quantificacional” (Huitink 2009: 20, tradução minha) ${ }^{11}$. Nesse caso, provavelmente parece ser próximo o bastante de dever e poder para permitir leituras com concordância modal com esses dois verbos. Em resumo, para que haja concordância modal é necessário que os elementos envolvidos compartilhem a mesma força modal (ou sejam próximos o bastante) e o mesmo tipo de modalidade veiculada.

\section{A função discursiva da concordância modal}

Nas seções anteriores, mostramos a sintaxe e a semântica das construções com concordância modal. Uma questão fica por responder: se construções com concordância modal (isto é, com dois

10. Esses dois exemplos foram extraídos de Hoye (1997: 97).

11. 'Perhaps the verb and the adverb only have to be 'close enough' in quantificational force" 
constituintes de natureza modal que são interpretados como se apenas um deles houvesse) são equivalentes semanticamente a construções em que há apenas um modal expresso, o que levaria o falante a escolher construções desse tipo em vez de escolher simplesmente construções mais transparentes com apenas um modal? Essa questão fica sem resposta se observarmos apenas o componente sintático e o semântico. Para entendermos o porquê de a gramática derivar tais sentenças, é necessário introduzirmos na nossa reflexão o componente discursivo porque, embora haja identidade semântica entre construções com e sem concordância modal, as sentenças com concordância modal apresentam um efeito discursivo bem delimitado: elas se associam a uma função discursiva de ênfase. Podemos ver essa função enfática nos exemplos a seguir:

26) P: O que vocês acham? Acertei 14 das 63 questões do ENEM, mas minha redação ficou horrível. Qual a explicação?

$\boldsymbol{R}$ : Para tirar notas boas, você obrigatoriamente deve ler revistas, jornais, notícias na internet, assistir telejornais e ter o hábito da leitura, pois a prova exige muito isso.

(27) P: Alguém sabe a diferença entre macroestrutura e microestrutura textual?

$\boldsymbol{R}$ : Macroestrutura diz respeito ao gênero, ou seja, à organização geral do texto, de tal forma que possa ser reconhecido como um dos gêneros existentes; por exemplo, um conto deve necessariamente se compor de episódios, personagem, tempo e espaço; uma carta já deve apresentar outra composição. (...)

(28) P: Meu computador está chiando para reproduzir áudio, o que fazer? De repente ele começou a chiar. Já testei outras caixas de som, mas mesmo assim todas ficam chiando, o que está acontecendo? E o que devo fazer?

$\boldsymbol{R}$ : Sua fonte de energia pode não estar suportando os 
componentes internos de seu PC. Se a fonte for genérica, possivelmente pode ser isso. (...)

(29) P: Como organizar o tempo para estudar para o vestibular? Qual a maneira mais viável para aproveitar o meu tempo livre para investir nos estudos? Aguardo respostas...

$\boldsymbol{R}$ : Quando eu estudei para o vestibular (e passei), impus regras a mim mesma. Eu tinha obrigatoriamente que estudar 6 horas por dia no mínimo...

Nos exemplos acima (bem como nos demais apresentados ao longo desse estudo) há concordância modal e também podemos ver fortemente a função discursiva de ênfase que a repetição de elementos modais traz. As construções com concordância modal podem ser tratadas como estruturas complexas que envolvem a articulação de três níveis linguísticos: o sintático que combina os itens modais, o semântico que interpreta dois itens, como se apenas um houvesse, e o discursivo que vai tomar a ocorrência adicional de um modal como uma pista para dar ênfase ao enunciado.

\section{Considerações finais}

O objetivo desse artigo foi responder à pergunta inicial que era sobre a existência de concordância modal em Português. Como vimos, o Português também apresenta a possibilidade de gerar expressões com concordância modal, isto é, a possibilidade de criar sentenças com mais de um item modal que na semântica são interpretados como se apenas um deles houvesse. Uma vez que os dados forneceram evidências para a existência da concordância modal, passamos a apresentar sua descrição e análise.

Da mesma forma que em outras línguas, esse fenômeno do ponto de vista sintático era bastante restrito: apenas construções em que havia dois elementos modais, sendo um deles obrigatoriamente um verbo auxiliar modal, podiam expressar a concordância modal. Em 
relação ao segundo elemento, vimos que o Português tanto pode usar outro verbo modal quanto um advérbio. Outra restrição é a de que os elementos envolvidos estivessem próximos, devendo estar no mesmo domínio oracional.

Do ponto de vista semântico, foi mostrado que esse fenômeno não é obrigatório, ou seja, a presença de um verbo auxiliar modal e outro elemento modal em uma mesma oração nem sempre garante a concordância modal. Nos casos em que se verifica esse tipo de concordância, duas condições devem ser satisfeitas: os elementos envolvidos devem partilham a mesma força quantificacional e o mesmo tipo de modalidade.

Para entender melhor o fenômeno em estudo, fez-se necessária a introdução do componente discursivo para mostrar que essas estruturas têm um efeito muito bem definido: elas trazem ênfase ao enunciado.

\section{Referências Bibliográficas}

Baker, C. Learnability and the English auxiliary system. In: Baker, C. \& McCarthy, J. (eds.) The Logical Problem of Language Acquisition. Cambridge, MA: MIT Press, 1981, p. 296-323.

von Fintel, K. Modality and Language. In: Borchert, D. (ed.). Encyclopedia of Philosophy. Detroit: MacMillan, 2006, p. 20-27.

von Fintel, K \& Iatridou, S. What to do if you want to go to Harlem: Notes on anankastic conditionals and related matters. MIT, 2005. Disponível em: <http://web.mit.edu/fintel/www/harlem.pdf> Acesso em 27/09/2010.

Geurts, B. \& Huitink, J. Modal concord. In: Dekker, P \& Zeijstra, H. (eds.) Proceedings of the ESSLLI 2006 Workshop Concord Phenomena at the Syntax Semantics Interface. 15-20. University of Malaga, 2006, p. 15-20.

Hacquard, V. (no prelo). Modality. A sair em: Maierborn, C; von Heusinger, K \& Portner, P. (eds.) Semantics: An International Handbook of Natural Language Meaning. Berlin: Walter De Gruyter. 
Hacquard, V. Aspects of Modality. Tese de Doutorado. Cambridge, MA: Massachusetts Institute of Technology.

Halliday, M. Functional diversity in language as seen from a consideration of modality and mood in English. Foundations of Language, 6: 332-361, 1970.

Hockett, C. The origins of speech. Scientific American, 203: 89-97, 1960.

Hoye, L. Adverbs and Modality in English. London and New York: Longman, 1997.

Huitink, J. Modal concord: a case study of Dutch. Frankfurt: Goethe Universität, 2009. Disponível em: < http://user.uni-frankfurt.de/ huitink/ Huitink-modalconcord.pdf > Acesso em 10/06/2010.

Kratzer, A. Modality. In: von Stechow, A. \& Wunderlich, D. (eds.). Semantics: an international handbook of contemporary research, Berlin: Mouton de Gruyter, 1991, p. 639-650.

Kratzer, A. The notional category of modality. In: Eikmeyer, H.-J. \& Rieser, H. (eds.) Words, Worlds, and Contexts. New Approaches in Word Semantics. Berlin: Mouton de Gruyter, 1981, p. 38-74.

Kratzer, A. What must and can must and can mean. Linguistics and Philosophy, 1(3): 337-355, 1977.

Lewis, D. Counterfactuals. Cambridge, MA: Harvard University Press, 1973.

Lightfoot, D. How to Set Parameters: Arguments from language change. Cambridge, MA: MIT Press, 1991.

Lightfoot, D. Principles of Diachronic Syntax. Cambridge: Cambridge University Press, 1979.

Lobato, L. Os verbos auxiliares em português contemporâneo: critérios de auxiliaridade. In: Lobato, L. et alii. Análises Lingüísticas. Petrópolis: Vozes, 1975, p. 27-91.

Lunguinho, M. A Ordem dos Verbos Auxiliares: uma análise em termos de traços. Dissertação de Mestrado. Brasília: Universidade de Brasília, 2005.

Lyons, J. Semantics. Cambridge: Cambridge University Press, 1977.

McCawley, J. Tense and time reference in English. In: Fillmore, C. \& Langendoen, T. (eds.) Studies in Linguistics Semantics. New York: Holt, Rinehart \& Winston, 1971, p. 96-113.

Miranda, Z. Aspectos do Comportamento Sintático dos Modais dever e poder. 
Dissertação de Mestrado. Campinas: Universidade Estadual de Campinas, 1975.

Palmer, F. Mood and Modality. Cambridge: Cambridge University Press, 1986.

Pires de Oliveira, R. \& Ngoy, F. Notas sobre a semântica do sufixo -vel: a expressão da modalidade no PB. Revista Letras, 73: 185-201, 2007.

Pontes, E. Verbos Auxiliares em Português. Petrópolis: Vozes, 1973.

Pullum, G. \& Wilson, D. Autonomous syntax and the analysis of auxiliaries. Language 53(4): 741-788, 1977.

Roberts, I \& Roussou, A. Syntactic Change: a minimalist approach to grammaticalization. Cambridge: Cambridge University Press, 2003.

Roberts, I. Agreement parameters and the development of English modal auxiliaries. Natural Language and Linguistic Theory, 3: 21-58, 1985.

Schachter, P. Explaining auxiliary order. In: Heny, F. \& Richards, B. (eds.) Auxiliaries and Related Puzzles. Volume II. Dordrecht: Reidel, 1983, p.145204.

Stowell, T. Tense and modals. In: Guéron, J. \& Lecarme, J (eds.) The Syntax of Time. Cambridge, MA: MIT Press, 2004, p. 621-635.

Tavares de Macedo, A. Dois Modelos de Análise para os Auxiliares em Português.

Dissertação de Mestrado. Rio de Janeiro: Universidade Federal do Rio de Janeiro, 1972.

Zeijlstra, H. Modal concord. In Friedman, T. \& Gibson, M. Proceedings of SALT XVII.

Ithaca, NY: Cornell University, 2007, p. 317-332.

Recebido em: julho de 2010 Aprovado em: outubro de 2010 marcuslunguinho@gmail.com 